\title{
ANALISIS TEMPERATUR LINGKUNGAN TERHADAP KINERJA COOLING TOWER TIPE INDUCED DRAFT UNIT 2 PADA PT. $X$.
}

\author{
,Mohamad Azfijam Irawan ${ }^{1}$ Harwan Ahyadi $^{2}$ \\ Teknik Mesin S1, Institut Sains Dan Teknologi Nasional \\ Jl. Moh. Kahfi II, Srengseng Sawah, JakartaSelatan 12630 \\ moh.azfijam.irawan@gmail.com ${ }^{1}$, \\ harwanfti@yahoo.co.id ${ }^{2}$
}

\begin{abstract}
Cooling tower is very necessary in every industry, especially in the geothermal power plant industry in the framework of implementation for efficiency and energy conversion where a tool or unit is used for circulation of cooling water. The function of the cooling tower is to process hot water into cold water, so that it can be used again. In the cooling tower specification data, the range value is $16.7^{\circ} \mathrm{C}$, with an approach of $6.5^{\circ} \mathrm{C}$, and with an efficiency of $71.98 \%$. The results of the calculation of the analysis obtained a range value of $22.3^{\circ} \mathrm{C}$, with an approach of $6.3^{\circ} \mathrm{C}$, and with an efficiency of $77.97 \%$. From the results of the analysis, the range, approach, and efficiency values were increased by $5.92 \%$ compared to the cooling tower specification data.
\end{abstract}

Keywords: Cooling Tower, Inducted Draft, Range, Approach, Efficiency

\begin{abstract}
ABSTRAK
Cooling tower ini sangat diperlukan di setiap industri khususnya industri pembangkit listrik tenaga panas bumi dalam rangka pelaksanaan untuk efisiensi dan konversi energi dimana digunakan suatu alat atau unit yang digunakan untuk sirkulasi air pendingin. Fungsi cooling tower adalah memproses air yang panas menjadi air dingin, sehingga dapat digunakan kembali. Penelitian dilakukan dengan mengambil data dengan mengukur debit air ,temperature air masuk dan temperature air keluar,dengan nilai range sebesar 16, $7{ }^{\circ} \mathrm{C}$, dengan approach sebesar $6,5{ }^{\circ} \mathrm{C}$, dan dengan efisiensi sebesar $71.98 \%$.Dari analisis diperoleh nilai range sebesar 22,3 ${ }^{\circ} \mathrm{C}$, dengan approach sebesar $6,3{ }^{\circ} \mathrm{C}$, dan dengan efisiensi sebesar 77,97\%. Dari hasil analisis maka didapat nilai range, approach, dan efisiensi mengalami kenaikan sebesar 5,92\% jika dibandingkan dengan data spesifikasi cooling tower.
\end{abstract}

Kata kunci : Cooling Tower, Inducted Draft, Range, Approach, Efisiensi 


\section{PENDAHULUAN}

Energi listrik merupakan suatu kebutuhan yang sangat diperlukan masyarakat. Segala aktifitas selalu berhubungan dengan pemanfaatan energi listrik. Untuk pembangkitanya sendiri di Indonesia, listrik dapat dihasilkan dari pemanfaatan batu bara, minyak bumi, air, angin serta panas bumi. Semua sumber energi tersebut tersedia melimpah di Indonesia.untuk panas bumi atau geotermal memiliki potensi yang sangat besar untuk dikembangkan dan dapat dimanfaatkan untuk skala besar. Energi geotermal dihasilkan dari inti perut bumi akibat terjadinya aktivitas magma.

Cooling tower ini sangat diperlukan di setiap industri khususnya industri Pembangkit listrik tenaga panas bumi dalam rangka pelaksanaan untuk efisiensi dan konversi energi dimana digunakan suatu alat atau unit yang digunakan untuk sirkulasi air pendingin. Air pendingin yang berasal dari alat atau sistem penukar panas didinginkan di menara pendingin dengan cara mengontakkan dengan udara yang dilewatkan bila zat cair panas dikontakkan dengan gas tak jenuh, sebagian dari zat cair itu akan menguap dan suhu zat cair akan turun. Fungsi cooling tower adalah memproses air yang panas menjadi air dingin, sehingga dapat digunakan kembali.

Penelitian untuk menganalisis yang berkaitan dengan pengaruh temperature lingkungan terhadap cooling tower serta faktor-faktor yang mempengaruhi kinerja cooling tower, antara lain: pengaruh temperatur ambient (dry bulb dan wet bulb). Pengukuran efektifitas dilakukan dengan memperhatikan dua hal penting yaitu nilai approach dan nilai range. Range merupakan perbedaan atau jarak antar temperature air masuk dan keluar menara pendingin, jadi nilai Range yang tinggi berarti bahwa menara pendingin telah mampu menurunkan suhu air secara efektif dan kinerjanya baik, Sedangkan Approach adalah perbedaan suhu air dingin keluar menara pendingin dan suhu wetbulb ambient, semakin rendah approach semakin baik kinerja cooling tower.

\section{METODA}

Penelitian dilakukan pada pembangkit litrik tenaga Panas Bumi (PLTP)"Kamojang PLTP Gunung Salak,Penelitia dilkukan pada bulan MeiJuni 2109.

Dalam penelitian pertama-tama yang dilakukan degan melukakan survey lapangan dengan alat-alat yang dipergunakan flow meter, temperature dan kelemababan serta peralatan yang akan dilalukan penelitian adalah cooling Tower dengan jenis induce draft double flow crosflow. Air kondensat keluaran dari kondensor akan dipompakan oleh dua buah pompa pendingin utama (main cooling water pump) ke cooling tower. Di atas cooling tower terdapat dua bak air panas (hot water basin) sehingga aliran air yang melewati pipa utama kan di bagi menjadi dua aliran ketika berada diatas cooling tower. Air panas akan mengalir melewati nozel-nozel secara gravitasi. Kemudian air ini akan jatuh dan kontak langsung dengan udara pendingin melalui fiil. Aliran udara yang mendinginkan air berlawanan arah dengan aliran air. Dengan menggunakan fan yang dipasang di atas akan menarik udara yang berasal dari udara luar untuk mendinginkan air panas. Fan akan menarik udara panas yang ada di dalam cooling tower untuk keluar dari cooling tower melalui fan stack sehingga uap panas akan dengan cepat keluar dan diganti dengan udara yang lebih tinggi. Dan selanjutnya air dingin akan dikumpulkan di bak air pendingin (cold water basin) yang berada di bawah cooling tower untuk disirkulasikan kembali ke kondensor.

Sumber pasokan air sebagai make up water dari sungai Cisaketi. Kapasitas air yang dibutuhkan oleh cooling tower adalah sebesar $2.825 .283 \mathrm{~m}^{3} / \mathrm{h}$. dengan lebar basin cooling tower sebesar 1,65 - $2 \mathrm{~m}$. Adapun penyelesain dalam penelitian dipergunakan rumus-rumus sebagai berikut :

\section{COOLING TOWER}

Bagian ini menjelaskan tentang bagaimana kinerja tenaga pendinginan dapat dikaji. Kinerja cooling tower di evaluasi untuk mengkaji tingkat approach dan range saat ini terhadap nilai desain, mengidentifikasi area terjadinya pemborosan energi dan memberikan saran perbaikan. Selama evaluasi kinerja, peralatan pemantauan yang portable digunakan untuk mengukur parameter-parameter berikut :

- Menghitung range dan approach Range dan approach temperature tersaji pada gambar 1 .

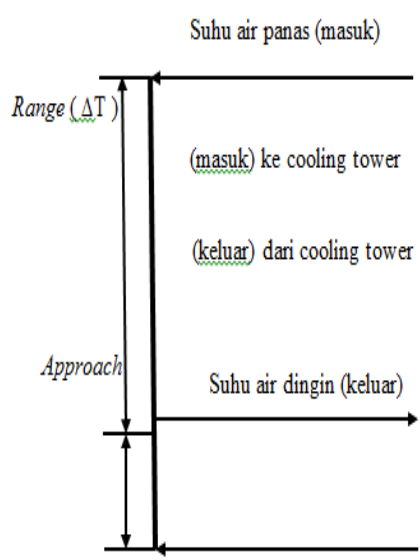

Gambar 1 Range dan Approach Temperature 


\section{- Range}

Untuk mengetahui nilai range cooling tower ini, harus mengetahui terlebih dahulu nilai dari temperatur air masuk $\left(T_{\text {in }}\right)$ dan temperatur air keluar $\left(\mathrm{T}_{\text {out }}\right)$. Temperatur air masuk $\left(\mathrm{T}_{\text {in }}\right)$ dan temperatur air keluar $\left(\mathrm{T}_{\text {out }}\right)$ ini memiliki nilai batasan. Untuk temperatur air masuk $\left(\mathrm{T}_{\text {in }}\right)$ memiliki suhu ideal antara $40^{\circ} \mathrm{C}$ $55^{\circ} \mathrm{C}$, temperatur air menurunkan temperatur air secara efektif, dan kinerjanya bagus. $U$ masuk $\left(T_{i n}\right)$ ini tidak boleh kurang dari $40^{\circ} \mathrm{C}$ dan juga tidak boleh lebih dari $55^{\circ} \mathrm{C}$.

Karena apabila suhu air masuk kurang dari $40^{\circ} \mathrm{C}$, maka akan mengakibatkan suhu air menjadi kurang panas yang akan menyebabkan berkurangnya uap yang akan dihasilkan oleh PLTP.

Sedangkan jika temperatur air masuk $\left(T_{\text {in }}\right)$ ini melebihi $55^{\circ} \mathrm{C}$ maka akan mengakibatkan suhu air menjadi sangat panas, yang akan menyebabkan pipa uap bocor karena terlalu banyak uap yang diproduksi. Dan untuk temperatur air keluar $\left(\mathrm{T}_{\text {out }}\right)$ memiliki suhu ideal antara 26 $\mathrm{C}-30^{\circ} \mathrm{C}$. Temperatur air keluar $\left(\mathrm{T}_{\text {out }}\right)$ ini tidak boleh kurang dari $26^{\circ} \mathrm{C}$, karena akan mengalkibatkan suhu air menjadi terlalu dingin. Sedangkan jika temperatur air keluar $\left(\mathrm{T}_{\text {out }}\right)$ melebihi $30^{\circ} \mathrm{C}$ maka akan mengakibatkan suhu air menjadi hangat, yang akan menyebabkan sistem pendingin tidak bekerja optimal. .Untuk menghitung range cooling tower dapat menggunakan persamaan 2.1

Range $\mathrm{CT}=\left[\mathrm{T}_{\text {in }}-\mathrm{T}_{\text {out }}\right]$

Dimana

Range $\mathrm{CT}=$ Range cooling tower $\left({ }^{\circ} \mathrm{C}\right)$

Tin=Temperatur masukcooling tower $\left({ }^{\circ} \mathrm{C}\right)$

Tout=Temperatur keluar cooling tower $\left({ }^{\circ} \mathrm{C}\right)$

\section{- Approach}

Untuk menghitung approach cooling tower dapat menggunakan persamaan 2.2.

Approach CT $=[$ Tout $-\mathrm{Twb}]$

Dimana :

Approach $\mathrm{CT}=$ Approachcooling tower $\left({ }^{\circ} \mathrm{C}\right)$

$\mathrm{Twb}=$ Temperatur wet bulb cooling tower $\left({ }^{\circ} \mathrm{C}\right)$

\section{- Efektifitas}

Merupakan perbandingan antara range dan range ideal (dalam persentase), yaitu perbedaan antara temperatur masuk air pendingin dan temperatur wet bulb ambien, atau dengan kata lain adalah = Range/(Range + Approach). Semakin tinggi perbandingan ini, maka semakin tinggi efektifitas menara pendingin. Untuk menghitung efektivitas cooling tower dapat menggunakan persamaan 2.3

Efektifitas Cooling Tower $(\%)=$ $100 \% \times$

$\frac{T_{\text {in }}-T_{\text {out }}}{\left(T_{\left.\text {in }-T_{\text {out }}\right)+\left(T_{\text {out }}-T_{\text {wb }}\right)}\right)}$

\section{- Kapasitas Pendinginan (Qct)}

Merupakan jumlah panas yang dibuang dari air, sebagai hasil dari kecepatan aliran massa air, panas spesifik dan perbedaan suhu. Untuk menghitung kapasitas pendingin pada cooling tower dapat menggunakan persamaan 2.4

Qct $=\operatorname{mct} x($ Tin - Tout $)$

Dimana :

met = Laju aliran massa pada cooling tower $(\mathrm{kg} / \mathrm{h})$

\section{- Rugi Penguapan (We)}

Merupakan jumlah air yang diuapkan agar terjadi pendinginan. Jumlah air yang menguap dipengaruhi oleh panas laten air itu sendiri. Apabila semakin besar jumlah kalor yang diserap oleh cooling tower maka semakin besar juga kehilangan penguapannya. Begitupun sebaliknya, semakin sedikit jumlah kalor cooling tower maka akan sedikit juga kehilangan penguapanya. Hal ini disebabkan oleh faktor dari suhu lingkungan, dimana apabila pada pagi hari kehilangan penguapan pada yang kecil. Tapi apabila pada siang hari, tower memiliki nilai yang tinggi. Untuk menghitung rugi penguapan tower dapat menggunakan persamaan 3.5

Rugi Penguapan (m3/jam)

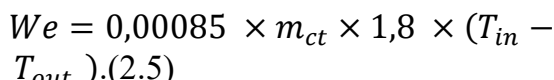

\section{HASIL DAN PEMBAHASAN} 3.1.Spesifikasi Data

Dari hasil data aktual yang diambil pada tanggal 13 - 19 Desember 2018, data design sudah terlampir pada table 1 spesifikasi thermal cooling tower. Data aktual yang diambil adalah sebagai berikut yang terlampir pada tabel Tabel 1 dan 2 Data Pengamatan Cooling Tower Jam 12.00 
Tabel 1 Data Pengamatan Cooling Tower Jam 12.00

\begin{tabular}{|c|c|c|c|c|c|c|c|}
\hline \multirow{2}{*}{ Tanggal } & T/h & Bar & ${ }^{\circ} \mathrm{C}$ & ${ }^{\circ} \mathrm{C}$ & ${ }^{\circ} \mathrm{C}$ & kj/kg & kj kg \\
\cline { 2 - 8 } & mctim & $\mathrm{P}_{\text {in }}$ & $\mathrm{T}_{\text {in }}$ & $\mathrm{T}_{\text {out }}$ & $\mathrm{T}_{\text {wb }}$ & $\mathrm{H}_{\text {in }}$ & $\mathrm{H}_{\text {out }}$ \\
\hline 13 & 9793 & 2.2 & 54.4 & 31.9 & 23 & 227.7 & 133.7 \\
\hline 14 & 9582 & 2.1 & 54.2 & 31.8 & 23 & 226.9 & 133.3 \\
\hline 15 & 9447 & 2.2 & 53.6 & 31.3 & 25 & 224.4 & 131.2 \\
\hline 16 & 9558 & 2.2 & 53.4 & 31.2 & 21 & 223.6 & 130.8 \\
\hline 17 & 9133 & 2.2 & 53.6 & 31.1 & 22 & 224.4 & 130.3 \\
\hline 18 & 9037 & 2.1 & 54.2 & 31.5 & 25 & 226.9 & 136 \\
\hline 19 & 9190 & 2.1 & 54.4 & 31.6 & 22 & 227.7 & 132.4 \\
\hline
\end{tabular}

Tabel 2 Data Pengamatan Cooling Tower Jam 00.00

\begin{tabular}{|c|c|c|c|c|c|c|c|}
\hline \multirow{2}{*}{ Tanggal } & $\mathrm{T} / \mathrm{h}$ & $\mathrm{Bar}$ & ${ }^{\circ} \mathrm{C}$ & ${ }^{\circ} \mathrm{C}$ & ${ }^{\circ} \mathrm{C}$ & $\mathrm{kj} / \mathrm{kg}$ & $\mathrm{kj} / \mathrm{kg}$ \\
\cline { 2 - 8 } & mctim & Pin & Tin & Tout & Twb & Hin & Hout \\
\hline 13 & 9922 & 2.2 & 53.1 & 30.9 & 19 & 222.3 & 129.51 \\
\hline 14 & 9702 & 2.2 & 53.1 & 30.8 & 18 & 222.3 & 129.09 \\
\hline 15 & 9804 & 2.2 & 52.6 & 30.5 & 20 & 220.21 & 127.83 \\
\hline 16 & 8816 & 2.2 & 51.8 & 29.7 & 16 & 216.86 & 124.45 \\
\hline 17 & 9124 & 2.2 & 51.7 & 30.2 & 21 & 216.44 & 126.58 \\
\hline 18 & 8918 & 2.2 & 52.2 & 30 & 20 & 218.53 & 125.74 \\
\hline 19 & 8987 & 2.2 & 52.3 & 29.8 & 19 & 218.95 & 124.91 \\
\hline
\end{tabular}

\subsection{Hasil perhitungan Efektifitas Cooling}

\section{Tower diperoleh}

Dimana diperoleh data sebagai berikut :

$$
\begin{aligned}
& \text { - Tin }=53,6^{\circ} \mathrm{C} \\
& \text { - Tout }=31,3{ }^{\circ} \mathrm{C} \\
& \text { - Twb }=25^{\circ} \mathrm{C}
\end{aligned}
$$

Penyelesaian :

$$
\begin{array}{ll}
\text { 1. Range }\left({ }^{\circ} \mathrm{C}\right) & =\left(\operatorname{Tin}^{\circ} \mathrm{C}-\text { Tout }^{\circ} \mathrm{C}\right) \\
& =(53,6-31,3) \\
& =22,3{ }^{\circ} \mathrm{C} \\
\text { 2. Approach }\left({ }^{\circ} \mathrm{C}\right) & =\left(\text { Tout }^{\circ} \mathrm{C}-\operatorname{Twb}^{\circ} \mathrm{C}\right) \\
& =(31,3-25) \\
& =6,3{ }^{\circ} \mathrm{C} \\
& =100 \% \times \frac{T_{\text {in }}-T_{\text {out }}}{\left(T_{\text {in }}-T_{\text {out }}\right)+\left(T_{\text {out }}-T_{w b}\right)} \\
& =100 \% \times \frac{\text { Range }}{(\text { Range }+ \text { Approach })} \\
& =100 \% \times \frac{22,3}{(22,3+6,3)} \\
& =77,97 \%
\end{array}
$$

Perhitugan selanjutnya dapat dilihat pada sajian tabel 3.
Tabel 3. Hasil Perhitungan Kalor yang Diserap

\begin{tabular}{|c|c|c|}
\hline \multicolumn{3}{|c|}{ Efektifitas } \\
\hline Tanggal & Jam 00.00 & Jam 12.00 \\
\hline 13 Des 2018 & $65,10 \%$ & $71,70 \%$ \\
\hline 14 Des 2018 & $63,50 \%$ & $71,80 \%$ \\
\hline 15 Des 2018 & $67,80 \%$ & $78 \%$ \\
\hline 16 Des 2018 & $61,70 \%$ & $68,70 \%$ \\
\hline 17 Des 2018 & $70 \%$ & $71,20 \%$ \\
\hline 18 Des 2018 & $68,90 \%$ & $77,70 \%$ \\
\hline 19 Des 2018 & $67,60 \%$ & $70,40 \%$ \\
\hline
\end{tabular}

\subsection{Perhitungan Kalor Yang Diserap}

Dimana diperoleh data sebagai berikut :

$$
\begin{aligned}
& - \text { Hin }=224,39 \mathrm{kj} / \mathrm{kg} \\
& - \text { Hout }=131,18 \mathrm{kj} / \mathrm{kg} \\
& \text { - mct }=9447 \mathrm{~T} / \mathrm{h}
\end{aligned}
$$

Qct $=$ mct $\times($ Hin-Hout $)=9447 \mathrm{~T} / \mathrm{h} \times(224,39$ $\mathrm{kj} / \mathrm{kg}-131,18 \mathrm{kj} / \mathrm{kg})=880554.87 \mathrm{~T} / \mathrm{h}$

Dari hasil perhitungan di atas terlihat bahwa kemampuan cooling tower dalam menyerap kalor yang terkandung dalam condensate adalah sebesar $880554.87 \mathrm{~T} / \mathrm{h}$.

Hasil Perhitungan Kalor yang diserap pada waktu yang telah ditentukan dapat dilihat dalam sajian tabel 4

Tabel 4 Hasil Perhitungan Kalor yang Diserap.

\begin{tabular}{|c|c|c|}
\hline \multicolumn{3}{|c|}{ Kalor Yang Diserap } \\
\hline Tanggal & Jam 00.00 & Jam 12.00 \\
\hline 13 Des 2018 & $920662,38 \mathrm{~T} / \mathrm{h}$ & $920933,72 \mathrm{~T} / \mathrm{h}$ \\
\hline 14 Des 2018 & $904323,42 \mathrm{~T} / \mathrm{h}$ & $897066,84 \mathrm{~T} / \mathrm{h}$ \\
\hline 15 Des 2018 & $905693,52 \mathrm{~T} / \mathrm{h}$ & $880554,87 \mathrm{~T} / \mathrm{h}$ \\
\hline 16 Des 2018 & $814686,56 \mathrm{~T} / \mathrm{h}$ & $886886,82 \mathrm{~T} / \mathrm{h}$ \\
\hline 17 Des 2018 & $819882,64 \mathrm{~T} / \mathrm{h}$ & $858958,65 \mathrm{~T} / \mathrm{h}$ \\
\hline 18 Des 2018 & $827501,22 \mathrm{~T} / \mathrm{h}$ & $821192,19 \mathrm{~T} / \mathrm{h}$ \\
\hline 19 Des 2018 & $845137,48 \mathrm{~T} / \mathrm{h}$ & $875807 \mathrm{~T} / \mathrm{h}$ \\
\hline
\end{tabular}

\subsection{Perhitungan Evaporation Loss}

Dimana diperoleh data sebagai berikut :

$$
\begin{array}{ll}
-\quad \text { Tin } & =53,6^{\circ} \mathrm{C} \\
-\quad \text { Tout } & =31,3{ }^{\circ} \mathrm{C} \\
-\quad \text { mct } & =9447 \mathrm{~T} / \mathrm{h}
\end{array}
$$

Penyelesaian : 


$$
\begin{array}{ll}
\text { We } & =0,00085 \times m_{c t} \times 1,8 \times\left(T_{\text {in }}-T_{\text {out }}\right) \\
\text { We } & =0,00085 \times 9447 \times 1,8 \times(53,6-31,3) \\
\text { We } & =322,32 \mathrm{~m}^{3} / \mathrm{jam}
\end{array}
$$

Hasil perhitungan evaporation loss setiap waktu penelitian dapat dilihat pada sajian tebel 5

\begin{tabular}{|c|c|c|}
\hline \multicolumn{3}{|c|}{ Evaporation Loss } \\
\hline Tanggal & Jam 00.00 & Jam 12.00 \\
\hline 13 Des 2018 & $337,01 \mathrm{~m}^{3} / \mathrm{jam}$ & $337,12 \mathrm{~m}^{3} / \mathrm{jam}$ \\
\hline 14 Des 2018 & $331,02 \mathrm{~m}^{3} / \mathrm{jam}$ & $328,39 \mathrm{~m}^{3} / \mathrm{jam}$ \\
\hline 15 Des 2018 & $331,5 \mathrm{~m}^{3} / \mathrm{jam}$ & $322,32 \mathrm{~m}^{3} / \mathrm{jam}$ \\
\hline 16 Des 2018 & $298,1 \mathrm{~m}^{3} / \mathrm{jam}$ & $327,57 \mathrm{~m}^{3} / \mathrm{jam}$ \\
\hline 17 Des 2018 & $300,13 \mathrm{~m}^{3} / \mathrm{jam}$ & $314,4 \mathrm{~m}^{3} / \mathrm{jam}$ \\
\hline 18 Des 2018 & $302,91 \mathrm{~m}^{3} / \mathrm{jam}$ & $313,86 \mathrm{~m}^{3} / \mathrm{jam}$ \\
\hline 19 Des 2018 & $309,38 \mathrm{~m}^{3} / \mathrm{jam}$ & $320,58 \mathrm{~m}^{3} / \mathrm{jam}$ \\
\hline
\end{tabular}
dibawah ini

Tabel 5 Hasil Perhitungan Evaporation Loss

\subsection{Pembahasan}

Dari hasil perhitungan dilanjutkan dalam pembahasan

\section{5.a. Analisis Perhitungan Efektifitas Cooling Tower}

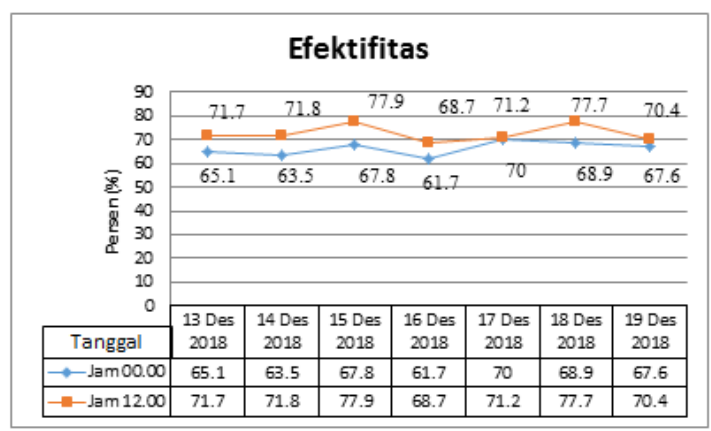

\section{Gambar 3 Grafik Efektifitas Cooling Tower}

Jika dilihat pada sajian gambar 3 menunjukan bahwa nilai Efektifitas (\%) terendah memiliki nilai sebesar $61,7 \%$ pada tanggal 16 Desember 2018 pukul 00.00 dan memiliki nilai Efektifitas tertinggi $77,9 \%$ pada tanggal 15 Desember 2018 pukul 12.00. Dari nilai tersebut dapat dikatakan nilai efektifitas cooling tower pada siang hari lebih baik daripada malam hari, karena untuk dapat dikatakan baik nilai efektifitas haruslah diatas $70 \%$.

\section{5.b.Analisis Perhitungan Kalor Yang Diserap}

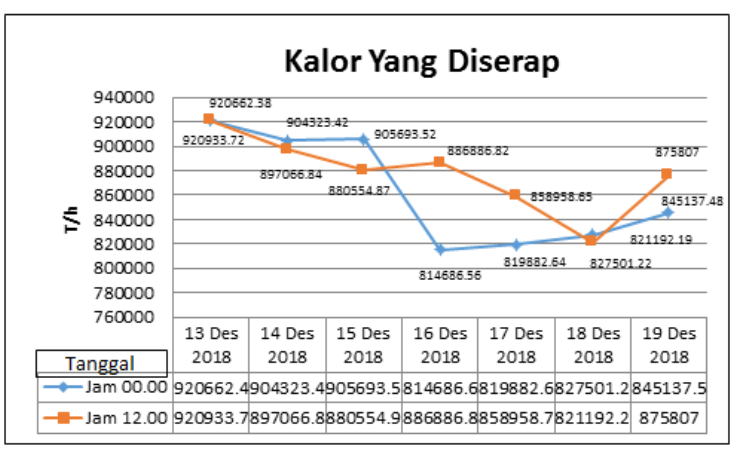

Gambar 4. Grafik Perhitungan Kalor Yang Diserap

Pada sajian gambar 4. dapat disimpulkan bahwa kemampuan tertinggi cooling tower dalam menyerap kalor yang terkandung dalam condensate adalah sebesar 920933,72 $\mathrm{T} / \mathrm{h}$ pada tanggal 13 Desember 2018 jam 12.00 dengan temperatur lingkungan sebesar $23^{\circ} \mathrm{C}$. Sedangkan kemampuan terendah cooling tower dalam menyerap kalor yang terkandung dalam condensate adalah sebesar $814686,56 \mathrm{~T} / \mathrm{h}$ pada tanggal 16 Desember 2018 jam 00.00 dengan temperatur lingkungan sebesar $16^{\circ} \mathrm{C}$.

\section{5.c. Evaporator Loss}

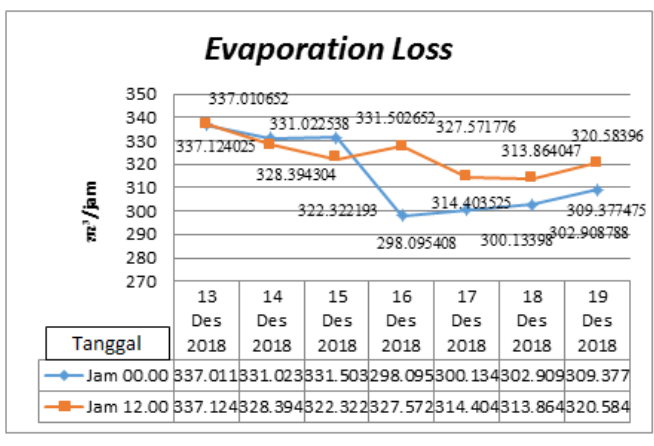

Gambar 5. Grafik Perhitungan Evaporation Loss

Pada sajian gambar gambar 5 bahwa nilai kehilangan penguapan (evaporation loss) terendah pada tanggal 16 Desember 2018 jam 00.00 sebesar $298,1 \mathrm{~m}^{3} / \mathrm{jam}$ dengan temperatur lingkungan sebesar $16^{\circ} \mathrm{C}$. Sedangkan nilai kehilangan penguapan (evaporation loss) tertinggi pada tanggal 13 Desember 2018 jam 12.00 sebesar $337,12 \mathrm{~m}^{3} / \mathrm{jam}$ dengan temperatur lingkungan sebesar $23^{\circ} \mathrm{C}$. 


\section{SIMPULAN} berikut :

Dari hasil analisis dapat disimpulkan sebagai

1.Pada data design temperatur air masuknya (Tin) memiliki nilai $42.7{ }^{\circ} \mathrm{C}$, dan temperatur air keluarnya (Tout) memiliki nilai $26^{\circ} \mathrm{C}$. Sehingga dapat dikatakan bahwa temperatur air masuk dan temperatur air keluar pada data design dalam keadaan baik, karena berada diantara suhu idealnya yaitu untuk temperatur air masuk memiliki suhu ideal antara $40{ }^{\circ} \mathrm{C}-55^{\circ} \mathrm{C}$. dan untuk temperatur air keluar memiliki suhu ideal antara $26^{\circ} \mathrm{C}-35^{\circ} \mathrm{C}$.

2.Pada data aktual temperatur air masuknya (Tin) memiliki suhu terendah sebesar $51,7^{\circ} \mathrm{C}$ dan memiliki suhu tertinggi sebesar $54,4^{\circ} \mathrm{C}$ dan temperatur air keluarnya (Tout) memiliki suhu terendah sebesar $29,7^{\circ} \mathrm{C}$ dan memiliki suhu tertinggi sebesar $31,9^{\circ} \mathrm{C}$. Sehingga dapat dikatakan bahwa temperatur air masuk dan temperatur air keluar pada data aktual dalam keadaan baik, karena berada diantara suhu idealnya yaitu untuk temperatur air masuk memiliki suhu ideal antara $40^{\circ} \mathrm{C}-55 \mathrm{C}$, dan untuk temperatur air keluar memiliki suhu ideal antara $26^{\circ} \mathrm{C}-35^{\circ} \mathrm{C}$.

3.Apabila Semakin banyak jumlah kalor yang diserap cooling tower yaitu sebesar 920933,72 $\mathrm{T} / \mathrm{h}$ pada tanggal 13 Desember 2018 jam 12.00 maka kehilangan penguapan sebesar sebesar $337,12 \mathrm{~m}^{\wedge} 3 / \mathrm{jam}$ dengan temperatur lingkungan sebesar $23^{\circ} \mathrm{C}$. Semakin besar jumlah kalor yang diserap oleh cooling tower maka semakin besar juga kehilangan penguapannya, hal ini disebabkan oleh faktor suhu lingkungan.

\section{DAFTAR PUSTAKA}

1. American society of Heating Refrigeration and Air Conditioning Engineers. ASHRAE Handbook. 4th Edition. 2001

2. ASHRAE, ASHRAE Handbook 2007. HVAC Application Chapter

3. SI Edition, Atlanta:published by the American Society of Heating, Refrigerating, and Air Conditioning Engineers, Inc.

4. ANSALDO ENERGIA S.p.A, Section C Cooling Tower Operation / Maintenance, 2009

5. Departemen Pertambangan dan Energi, (1988), Proyek PLTP Kamojang Unit 2\&3 (2 x 55 MW), Jakarta.

6. Elvani, Sulistya. 2017. "Maintenance Pada Cooling Tower Di PT. Indonesia Power UPJP Kamojang”.Bandung: Politeknik Negeri Bandung.

7. Jaber H, Webb RL. 1989. "Design of Cooling Tower by Effectiveness-NTU Method". ASME J Heat Transf. 43 pp

8. John C Hensley. 2006. Cooling tower Fundamentals. SPX Cooling Technologies. Kansas. USA

9. Trika, Restu. 2016. "Prosedur Pemeliharaan dan Perbaikan Cooling Tower di PT. Indonesia Power UPJP Kamojang”. Bandung : Universitas Pasundan Bandung.

10. Maintenance Manual Cooling Tower Gunung Salak Unit 2.

11. Mulyadasari Viska, 2011, Cooling Tower Slection and Sizing, KLM Technology Group, Johor Baru 